\title{
Torn labial frenum in isolation not pathognomonic of physical abuse
}

\author{
What is the probability that a torn labial frenum is caused by physical \\ child abuse?
}

\author{
Maguire SA, Hunter B, Hunter LM, Sibert J, Mann MK, \\ Kemp AM. \\ Diagnosing abuse: a systematic review of torn frenum and \\ intra-oral injuries. Arch Dis Child 2007; 27 (in press)
}

Data source Searches were made for studies using Applied Social Sciences Index and Abstracts, Caredata (the social work and social care knowledge base), Child Data (the National Children's Bureau Database), the Cumulative Index to Nursing and Allied Health, Embase, Medline, the System for Information on Grey Literature in Europe, the TRIP database (www.tripdatabase.com), Sciences Citation Index, and ISI Proceedings (covers conference papers in all scientific and technical fields). Authors were contacted where necessary.

Study selection All studies of children 0-18 years with intra-oral injuries because of physical child abuse, and torn labial frena of any aetiology, in live and fatal cases were included. Review articles, expert opinion or guidelines that did not include primary evidence, studies with mixed adult and child data where the children's data could not be extracted, studies that addressed complications or management of abusive injuries, intra-oral injuries because of sexual abuse, thermal injuries or dental neglect were excluded.

Data extraction and synthesis Studies were reviewed by the Welsh Child Protection Systematic Review Group. Standardised data extraction and appraisal forms were used and a qualitative synthesis undertaken.

Results Nineteen out of 154 studies reviewed were included, representing 591 children. There were no comparative studies of accidental and abusive torn labial frenum to enable a probability of abuse to be determined. Nine studies documented abusive torn labial frena in 27 children, of whom 22 were younger than 5 years old and 24 had been fatally abused. Only a direct blow to the face was substantiated as a mechanism of injury. Two studies noted accidentally torn labial frena, both from intubation. Abusive intra-oral injuries were widely distributed to the lips, gums, tongue and palate and included fractures, intrusion and extraction of the dentition, bites and contusions.

Conclusions Current literature does not support the diagnosis of abuse based on a torn labial frenum in isolation. The intra-oral hard and soft tissue should be examined in all suspected abuse cases, and a dental opinion sought where abnormalities are found.ome of the traditional and normative predictors of successful outcomes.

\section{Commentary}

This article is very welcome and dispels the myth commonly held and reported in successive medical textbooks that a torn upper labial frenum is "pathognomonic of child abuse". Sabine Maguire and her co-authors have exhaustively researched the literature and found no basis for this erroneously held belief.

Two recent pieces of work involving the dental team and child protection have been party to the results of Maguire et al. Initially, the British Society of Paediatric Dentistry and the Royal College of Paediatrics and Child Health worked together to produce an advice sheet for the dental team. ${ }^{1}$ A more extensive document was then commissioned by the Chief Dental Officer (England) entitled Child Protection and the Dental Team. This latter document was produced by a multidisciplinary team led by Jenny Harris, a Specialist in Paediatric Dentistry, and at the current time has been distributed in hard copy to all general dental practices in England and Scotland and all primary care premises in Scotland. It is also available to all to download from the web (www.cpdt.org.uk). Minor differences exist in Scotland and these are covered in an addendum available for download at www.scottishdental.org/resources/child_protection.htm

Child Protection and the Dental Team states that, "a frenum tear in a very young non-ambulatory patient (less than 1 year) should arouse suspicion". This statement is of course even more important where no clear history of direct trauma is offered.

\section{Practice point}

- A torn labial frenum in isolation cannot be regarded as pathognomonic of physical abuse, and must be assessed in the context of the history given, and a full examination with appropriate investigations.

- The most common abusive injury to the mouth is laceration /bruising to the lips.

\section{Richard Welbury}

Department of Paediatric Dentistry, University of Glasgow Dental School. Glasgow, Scotland, UK

1. Welbury RR and Gregg TA. Child physical abuse. In Managing Dental Trauma in Practice. London: Quintessence; 2006:pp.99-109

Evidence-Based Dentistry (2007) 8, 5-6. doi:10.1038/sj.ebd.6400505 